\title{
The Body as a Selfing Device
}

\section{The Case of Anorexia Nervosa}

\section{Cor Baerveldt and Paul Voestermans}

UNIVERSITY OF NIJMEGEN

\begin{abstract}
Psychology's conceptualization of anorexia nervosa illustrates how the discipline deals with the body. On the one hand, there is an emphasis on the body as a physiological apparatus. On the other hand, specific approaches such as social constructionism stress the nonphysiological body as something to which certain discursive meanings get attached. We propose to view the body as a producer of meaning in its own right, as a 'selfing device'. To this end we emphasize bodily communication as a continuous flow of co-regulated interaction. The body presents itself as the natural juncture of 'co-regulative skills'. The 'selfing process' involves multiple stylized bodily skills that testify to people's ability to take part in the life-world. Anorexia is seen as a disturbance of those skills.
\end{abstract}

KEY WoRDS: anorexia nervosa, bodily skills, co-regulation, embodiment, social constructionism

Anorexia nervosa involves the body. The question is: which body? Is it just the biological apparatus or organism, as the body might be referred to, or the body as a means of expressing feelings and emotions and as a mode of selfpresentation? Or is it a combination? These are the probing questions for this paper. Not just the patient is involved bodily. Anorexia also presents a case for psychology's involvement with the body. However, the body as such is hardly a subject-matter for psychology. Psychology is a science 'buried in thought', locked up in phrases, so to speak. Insofar as science is a matter of searching for explanations, being buried in thought is not a problem, of course, but if the scientific focus is merely on what people think or talk about, psychology is robbed unduly of much of its material. The body presents a psychological world of its own, to which the case of anorexia nervosa will give us some access.

The adjective 'nervosa', which was included in the diagnostic label of this eating disorder right from the outset (Brumberg, 1988), suggests a belief in a kind of 'nervous' basis. Nervous did not imply bodily (neural) processes. Mental processes were included under that label as well. So the dispute centred immediately on the bodily vs the mental basis of the disorder. It has

Theory \& Psychology Copyright (9) 1996 SAge Publications. Vol. 6(4): 693-713 
remained this way until the present time in those literatures in which a materialistic stance on behavioural and psychological issues is played off against a mentalistic one. Social constructionist attempts to come to grips with anorexia nervosa have tended to circumvent this dualistic dispute by emphasizing that the body is a complex cluster of cultural constructions. In this case the medical and biological perspective on the body is enriched by one in which bodily states and functions are related to self and identity. In this paper we want to explore this new perspective in order to understand the role played by the body in ordinary ways of living. First, the social constructionist choice for the non-physiological body is discussed. The linguistic bias of social constructionism is criticized in order to explore the communicative aspects of the body in a much more refined way. In our view the body is a 'selfing' device. The neologism 'selfing' is used deliberately. Research on the self tends to ignore the process side of the self. The notion of 'selfing' attempts to capture the activities through which the person becomes a social and personal self. We argue that the body is important in that regard.

\section{The Body in Social Constructionism}

In contemporary psychological reflections on self and emotions, the body seems to play a minor role except in the age-old form of the 'soft machine, stuffed with tender little wires and tubes', to use an expression by the Dutch poet Leo Vroman (1957). Social constructionism unmistakably has something to say about the body, but rather polemically. Theories that assign an important role to the physiological body in the constitution of emotions and feelings are de-emphasized (Averill, 1980; Harré, 1986; Ratner, 1989). There is a difference in how physiology is played down, depending on whether the weak or strong, radical version of social constructionism is adopted (Armon-Jones, 1986; Terwee, 1995). Social constructionism in its 'weak' form does not deny the existence of a limited range of natural emotional responses. Yet proponents of this form seem to agree that human experience, including the experience of the body, can become meaningfully connected with a sense of self only within the context of a cultural system of beliefs and values (Armon-Jones, 1986; Hochschild, 1983; Sarbin, 1986a, 1986b). The 'strong' version of social constructionism denies the relevance of physiological processes altogether. Weak and strong constructionism alike try to limit the medical and biological usurpation of the body. All social constructionists argue that viewing the body from a medical or biological perspective can only limit the understanding of its role in the way humans live. But what, then, is this role? To put it more sharply, does the body have a role in the production of meaning? The answer to this question is pertinent to the way anorexia is dealt with. 
One thing is quite clear as far as the social constructionist perspective on the body is concerned: by contesting that physiology is central to the process of experiencing, body and physiology are implicitly equated. The two are collapsed and functional electro-chemical bodily processes have no bearing on the production of meaning, save for the fact that these processes are seen as merely conditional. It is quite obvious that, once certain bodily parts or systems are damaged, behavior will suffer as well.

In order to avoid the immediate drawback of a purely mentalistic view of meaning, social constructionism emphasizes a non-physiological body. From this perspective, the states and functions of the body become a cluster of cultural instead of natural, that is, biological, constructions. The formative and rhetorical aspects of language have a strong bearing on these cultural constructions. Language in, for example, the form of emotion talk and emotion words (Heelas, 1981; Lutz, 1986, 1988) or as narrative plots and everyday story-lines (Gergen \& Gergen, 1983, 1984, 1988; Sarbin, 1986a, $1986 \mathrm{~b}$ ) becomes the main locus of socially constructed meaning. Constructionists claim that these 'meanings' penetrate psychological life in all its facets. The body is a rather shallow participant in this scheme because it is introduced, for example, in the conception of an emotion as 'a bodily enactment of a moral judgment or attitude in accordance with the conventions of local dramatistic roles' (Harré, 1991, p. 142; Sarbin, 1986b). Put more generally, the structure and meaning of bodily conduct originate from discursively constructed cultural resources that provide the scripts carried out by bodily gestures and postures. As will be shown in a moment, this non-physiological, 'dramatistic' body, which is constructed discursively from cultural resources, has undergone an interesting fate that has had a strong bearing on anorexia nervosa.

\section{Politicizing the Social Constructionists' Body}

Since the appearance of Berger and Luckmann's book The Social Construction of Reality (1966), it has become understood among constructionists that meaning and knowledge are produced in social interactions. They have also stressed that meaning and knowledge are constitutive of those very same interactions. Social constructionists have tended to emphasize only this latter point. As a consequence, empirical research has been restricted mostly to the analysis of already produced texts (Sarbin, 1986a; Shotter \& Gergen, 1989). More recently, however, a shift of focus has occurred. The emphasis is no longer on culture as an already constructed linguistic order, but on the production and maintenance of meaning and identity in the course of everyday conversational interactions and discursive practices (Harré \& Gillett, 1994; Shotter, 1993, 1995). The dynamic and productive aspects of linguistic interactions are put to the fore. This implies an emphasis on 
conversation, conflicts, dilemmas and relations of power and domination (Billig, 1987, 1988; Edwards, 1991; Potter \& Wetherell, 1987). This political variant of social constructionism brought about a renewed interest in the human body. Feminist authors especially have used a constructionist or discursive framework in order to show how people are classified by reference to their bodies (Butler, 1990, 1993; Jaggar, 1983; Jaggar \& Bordo, 1992). Seemingly biological or naturally given categories like male/female and categories of sexual orientation such as 'homosexual', 'bisexual', 'gay' and 'lesbian' are revealed as being entirely socially constructed. The politicizing of the body goes along with an emphasis on the obedience of the body to the scripts of the dominant ethic, be it the ethic of heterosexuality, masculinity, femininity, but also of homosexuality, the submissive traditional female care-giving functions or dominant male public functions (Kitzinger, 1987, 1992; Unger, 1989, 1992). With this emphasis on body politics, the body is given a central place in psychological thought. Yet the question can be raised whether this politicizing still adheres to the general social constructionist perspective of a body to which meaning is added. Moreover, in this political outlook the body becomes meaningful only insofar as discursive meanings such as those depicted in the mass media or in social scientific and psychological discourse get attached to it. To exaggerate a bit, the body becomes a sort of mannequin which 'wears' the signs of sex, power, status, and the like, and as such serves as the battleground for body politics (Merwe \& Voestermans, 1995).

In this overview we have lumped together all the social constructionists, even though Harré, for example, is very different from Gergen and both differ from Shotter, to name only the most prominent constructionists. The point we are trying to make is that no matter what nuances can be seen in their texts, the body remains an entity to which socially constructed meanings are added. The question we want to raise now is: what are the consequences of this theoretical stance for the understanding of anorexia nervosa?

\section{Anorexia Nervosa and the Mannequin Body: Gains and Criticism}

A brief survey of the literature regarding anorexia nervosa shows that early explanations tended to psychologize the syndrome, neglecting both its cultural aspects and the body in its own right. Psychoanalytic explanations, for example, interpret anorexia as the fear of oral impregnation and the rejection of female sexuality (Thomä, 1967; Waller, Kaufman, \& Deutsch, 1940). From the 1950s onward, ego-psychological and object-relational 
interpretations of orality came to emphasize the process of separation from the mother in the development of solid ego boundaries. Anorexia was interpreted as the consequence of 'ego-weakness', which resulted in what Bruch (1974) has called 'a paralyzing sense of ineffectiveness'. During the 1970s ego-psychological approaches were broadened by positions that emphasized the social and cultural aspects of identity formation. SelviniPalazzoli (1974) and Minuchin, Rosman and Baker (1978) assigned a central role to communication patterns within the family system that hinder the development of an autonomous sense of identity. The mothers of anorectics especially were depicted as frustrated, over-protective women who did not acknowledge their daughters' autonomy (Bruch, 1978; Selvini-Palazzoli, 1974). Later feminist-oriented authors like Lawrence (1984) and Chernin (1986) pointed to the social position of modern, highly educated women, in which they are forced to conform both to the modern demands of a career and to those of traditional care-giving and motherhood. In particular, the role of the mother was reinterpreted by representing her as a woman who had been pressed by societal demands to give up her own ambitions and exclusively dedicate herself to the family. Both mother and daughter were seen as victims of a patriarchal society.

Current research into the genesis of anorexia has given up, for the most part, the attempt to explain from a single variable. Instead it is assumed that anorexia has multiple causes (Garfinkel \& Garner, 1982). Non-specific psychological factors like low self-esteem, perfectionism and social uncertainty all presumably contribute to the genesis of the syndrome. In most of these explanatory efforts the body plays a minor role. The nonphysiological body appears on the stage most often as the cultural ideal of thinness, pressing women to keep trying to lose weight. On the basis of an investigation of Playboy centrefolds and Miss America Pageant contestants in the period 1959-78, Garner, Garfinkel, Schwartz and Thompson (1980) demonstrated that a shift occurred to a more slender standard. More recently, the same trend was found for the years 1979-88 (Wiseman, Gray, Mosimann, \& Ahrens, 1992). Garner et al. suggested that the postwar increase in anorexia nervosa is partly due to these changing cultural ideals for beauty and success. Nevertheless, although the ideal of slenderness can probably throw some light on the question as to why so many women in our society are preoccupied with trying to lose weight, it falls short as an explanation of anorexia nervosa. It remains unclear how the cultural appreciation of the female body can penetrate into the subjective experience of the body to such an extent that it makes some women modify and even mutilate their own bodies. Moreover, the striking observation about anorexia is the fact that these women persist in their attempt to lose weight and yet continue to report that they feel fat. It is quite unlikely that the cultural standard of a slender female body continues to motivate them. Diaries and other ego- 
documents of anorectics (e.g. Dunbar, 1986; Macleod, 1982) show that the weight anorectic women set for themselves is constantly pushed downward, which suggests that they are striving for body control rather than aiming at some idealized body shape.

A central argument in feminist explanations of anorexia nervosa has been the politicizing of the body along the lines discussed above. Anorexia nervosa has been interpreted both as an over-identification with sex role stereotypes (Boskind-Lodahl, 1976) and as a symbolic protest against the social position of women in society, involving a dismissal of these very same stereotypes (Orbach, 1985). Both Orbach and Boskind-Lodahl state that the social judgment of fatness is inherently sexist. It reflects the dominant male discourse about preferred female body shape.

For Boskind-Lodahl the modification of the body is a symptom of social inadequacy and the lack of self-esteem due to social stereotypes of femininity. This perceived inadequacy and the fear of being rejected by their social environment cause some women to adopt a passive and accommodating approach to life and an obsession with appearance and body shape. At first, they try to lose weight in order to live up to the perceived preferences of men, but eventually slimming becomes a means of reducing fear and social uncertainty in general. Orbach considers the body a medium of communication, a way of expressing something which cannot be said in words. The anorectic's body carries a message, which should be read as a message of protest. Orbach explicitly uses the metaphor of the hunger strike to make this point.

Although both Boskind-Lodahl and Orbach emphasize that the body is a means of expression, it remains a mannequin and a battleground for body politics. In essence, the assignment of meaning takes place by an outside observer rather than by the anorectic herself. The message of protest has to be inferred from a political analysis. This means that the excessive slimming is in fact considered as symptomatic of a given social order, rather than as a way to communicate about, or to protest against, this social order. By politicizing the female body this way, the body as the expressive medium of a real person gets out of focus. The body becomes an arena of political dispute in which the anorectic herself doesn't take part as an individual (Lenning, 1990). Anorexia serves as the arena for 'identity politics' (Sampson, 1993), which takes place outside the psychological reality of the day to day practices of the anorectic herself that claim and sustain an identity in the course of everyday social interactions. Orbach persists in a view of the body as the bearer of meanings which are eventually produced in a discursive process. This process takes place without the anorectic being part of it. It acquires those meanings only within the context of a dominant sexist discursive order. In that regard the body merely represents the feminist challenge of that order. 


\section{Extending the Discursive Paradigm: The Body as Language}

The body as mannequin and the body as an arena for body politics both fail to explain how the body serves as a meaning-producing device in its own right. If we want to come to grips with the role of anorectics as women who are bodies of flesh and bones and do not just have a body as a cluster of politicized meanings attached to it, the body as a communicative device needs to be understood. One attempt to do exactly that is the social constructionist extension of the notion of discourse in such a way that it includes the communicative use of the body. Harre and Gillett (1994) proceeded that way and contended that it is a main thesis of discursive psychology that episodes in which psychological phenomena are brought into being by the use of nonlinguistic signs should be analyzed as if they were through and through linguistic' (p. 99). The implications of this contention for social constructionists' dealings with the body become apparent from Harré's design for a 'corporeal semantics'. He noted that '[t]he human body is such that its states, conditions, parts and postures serve as signs. It is both a semiotic system in itself and made meaningful by a semiotic system' (Harré, 1991, p. 223)

The claim that some sort of linguistics can provide a model for psychology in which the body is included is not new. Birdwhistell (1952), for example, stated long ago that 'it has to become clear that there are body behaviors which function like significant sounds, that combine into simple or relatively complex units like words, which are combined into much longer stretches of structured behavior like sentences or even paragraphs' (p. 80). The idea of bodily conduct as a patterned sequence of structural units, analogous to those of language, is also found in the work of Scheflen (1964).

Kristeva (1968/1978) was the first to criticize Birdwhistell for reducing communication to the exchange of information. She was particularly apprehensive about the reduction of praxis - the way people are immersed in their daily doings - to representations. A comparable critique was given more recently by Radley (1991). He explained that the restricted attention to body movements as communicative acts leaves out the possibility for analysing bodily conduct as a cultural practice in its own right. To further clarify this point, Radley criticized the reduction of non-verbal behaviour to communication. He referred to the contribution of Wiener, Devoe, Rubinow and Geller (1972), who pointed out that in the studies of non-verbal behaviour the notion of sign is easily confused with that of communication. Body movements or other bodily signs signal a certain state of affairs, but this is not the same as communication. What Wiener and others attempted to convey is that as soon as bodily conduct, which 'tells' the onlooker something about the person, is treated as a communicative act, the body of that person becomes an integral part of what the receiver perceives. On the 
perceiver's side a kind of message is decoded. Of course, we do that frequently - read off other people's bodily signs and cast them in a linguistic form. But by doing so our focus is entirely on the observer's (receiver's) judgements of certain postures or gestures. Through these judgements bodily movements and non-verbal signs are turned into something language-like, into linguistic communication. However, postures and gestures are not necessarily discursively produced. That may be the case when there is a deliberate effort, as in sign language. Yet a propositionally organized or argumentatively structured message, which subsequently generates signs, need not always be present. This last assertion is crucial for a new understanding of the body as a selfing device or a meaning-producing device. The recipient's understanding of bodily signs as a communication or as carrying a message should not be projected onto the producer's mind, as if it was this mind which formed messages by bodily means.

Radley was right in criticizing the rather self-evident practice of viewing non-verbal communication as linguistic communication. It becomes linguistic only by a rather specific and separate process. The notion of communication is also misleading. The process of the production of signs should not be confused with the process by which they are turned into a communicative message by the recipient's interpretation. In order to demarcate the notion of communication, Wiener et al. asserted that the signs of the body can rightfully be called communication only if the person who acts has the intention of making something public. Furthermore, she or he has to make use of a socially shared signal system or code in order to make this possible. In case these conditions are not met, bodily conduct should be considered as 'symptomatic' of a certain bodily state rather than being viewed as communication. Shivering, for example is 'symptomatic' of the fact that somebody is cold, but should not be considered as communication about feeling cold.

Anorexia nervosa is often viewed as symptomatic. Feminist explanations especially view the body of the anorectic as part of a social symptomatology. The body is a site of interest for investigators who want to understand subordination and power. The anorectic body refers to experiences of domination and submissiveness and therefore the body becomes symptomatic of particular social situations. It is a signalling system about what these women suffer from, one that is much more ornate than mere words, but a signalling system nevertheless. Anorexia is a sign that the sufferers are entrapped in certain demands that are made upon their bodies. The presence of strong cultural ideals, for example, causes the anorectic women to exaggerate the control over their bodies in order to live up to those standards. A body presentation is created that gives away the anorectic's lack of ego strength and betrays the submission to cultural demands (Chernin, 1986; Lawrence, 1984). In most literature this lack of ego strength is related to certain family dynamics in which the mother plays a crucial role 
(Bruch, 1978; Chernin, 1986; Lawrence, 1984; Selvini-Palazzoli, 1974). Moreover, it is stressed that the social and cultural system as a whole and not just the family itself is responsible for the way parental behaviour is entrapped in demands that are counterproductive with respect to the anorectic's ego.

By contrasting the symptomatic with communication proper, Wiener and others have drawn a line between communication and signalling a certain state of affairs. Communication is restricted to sending a message. Radley (1991, p. 85) showed that Wiener et al. opened up the possibility for asking questions about those forms of bodily conduct which are in their terms not communicative but symptomatic, although their main objective lies in the reconceptualization of communication. According to Radley, Wiener et al. seem not to have taken advantage of that possibility. He claimed that it is as important to try to discover the social underpinnings of those symptomatic aspects as it is for communication proper. In that sense the borderline between the two cannot be drawn as strictly as Wiener et al. suggested. What is defined as 'symptomatic' has its social underpinnings as well; or, at the very best, we cannot exclude this as a possibility. Studies into the history of manners and bodily practices, for example, show that seemingly symptomatic bodily processes, such as sneezing, spitting and belching, are in fact socially regulated (Elias, 1978). Radley asserted that a study of the body in social life should include the investigation of bodily styles and practices. Mauss already stated in his 1935 essay on 'the techniques of the body' that there exists an 'education of movements' which inscribes itself into expressive style of all bodily performances (Mauss, 1935/1973). It is this project of the culturally inscripted body that we want to pursue.

From the perspective of the anorectic, the body is involved in all kinds of social arrangements. These do not provide a passive background, but rather form the active context in which the so-called 'symptoms' are a form of bodily meaning production that should not be ignored, even if an outside observer (receiver) fails to catch this meaning. Therefore, we would like to broaden Wiener et al.'s restrictive view on communication in such a way that it includes all bodily conduct which contributes to the production of meaning and which is somehow socially regulated. This broadening implies a redefinition of communication. The redefinition we would like to suggest is one in terms of 'co-regulation'.

\section{Communication as Co-regulation}

Wiener et al. rightly pose a question about the criteria of communication, but ultimately persist in what could be called the linguistic bias. They narrow their view to those modes of communication which rely on the use of a code or a socially shared signal system. It is obvious that this restriction excludes 
not only communicative behaviour as it is studied by ethologists, but also those forms of human expressivity which are non-discursive and nonpropositional. In her classical study on symbolism, Susan Langer (1951) had already demonstrated that discursive or linguistic symbolism is one way among others of communicating meaning. Others include the non-linguistic modes of symbolization Langer calls rituals. Ritual is a form of presentational instead of representational symbolism. While language involves the sequential combination of smaller structural units into larger ones, presentational symbolism cannot easily be split up into meaningful units. Presentational forms derive their meaning from the simultaneous coordination of the whole. The meaning of a presentational form like dance, for example, resides not in the combination of smaller behavioural units, but in the expressive quality of the movement as a whole.

In contrast to discursive meanings, presentational forms lack an explicit structure of the either/or kind. They can be considered forms with strong semantics and weak syntax. Therefore they cannot easily be translated into well-articulated statements of a discursive repertoire. Presentational forms can be found in artistic expression, dance and rituals, but also in everyday emotional expression.

That brings us to another reason why communication should be broadened to include those non-linguistic, presentational forms. By claiming that the encoder instead of the decoder of a message provides the final criterion of communication, Wiener et al. persist in the common metaphor of communication as something which is produced somewhere, subsequently transmitted through a communication channel, and finally delivered to a receiver. Fogel (1993) demonstrates that terms like 'sender', 'receiver' and 'signal' belong to the description of 'discrete state communication systems', in which the actors can only be in one of several clear-cut discretely different states (p. 27). In such systems, the actors alternately have to adopt the role of sender and receiver. Although this description may seem adequate in the case of the exchange of written messages like letters or formal oral communications such as debates, it falls short as a description of 'continuous process communications systems'. In a continuous process system it is impossible to determine who is the sender and who is the receiver. Instead the communication dynamically unfolds as a ceaseless flow of mutually induced action and adaptation. Fogel refers to this communicative process as 'co-regulation', 'the dynamic balancing act by which a smooth social performance is created out of the continuous mutual adjustment of action between partners' (p. 19). So the criterion to decide that a given interaction is communicative resides in the organization of the system as a whole and not in one of the participating actors. This point was already emphasized by Birdwhistell, who was indicted by Wiener et al. for not distinguishing between communications and signs. By restricting themselves to the communicative qualities of discrete informational units, Wiener et al. 
pass over in silence the actual flow of co-regulated action that specifies the communicative process.

A comparable point was put forward by Varela and Maturana (1984). They showed that the metaphor of communication as the transfer of information through discrete communication channels, appealing as it may seem in an age of mass media and flows of coded information, is both biologically and epistemologically inadequate. This view of communication presupposes that the behaviour produced by the sender is instructive with regard to what goes on at the receiver's end. Furthermore, the message is supposed to hold an informational content independent from the interpretation of the receiver or sender. However, it is quite obvious that the meaning of what is communicated is neither determined by the intentions of the sender, nor can it be found in the fixed relation between a sign and its conventional referent. Instead, it is dynamically produced in the communication process itself. Carrying on the phenomenological body project initiated by Merleau-Ponty, Varela and Maturana emphasize the embodied structure of meaning in the widest possible sense (Varela \& Maturana, 1984; Varela, Thompson, \& Rosch, 1991). Its essentially dialogical character, which points at a very vital co-construction of meaning, should not be overlooked (Hermans \& Kempen, 1993; Hermans, Kempen, \& Loon, 1992). To not account for this dialogical character of meaning in which both sides are emphasized reduces co-constructed meaning to information and coregulated action to mere instruction. All that is left is a message.

An important conclusion can be drawn from this co-regulative view of communication. It implies that a strong emphasis should be placed on what could be called 'co-regulative skills'. This type of skill should not be confused with the social skills or competence on which the social skill approach of mental health generally focuses. This approach relates mental disorders, like anorexia nervosa, to social inadequacy and a lack of social competence, especially the competence to deploy the body in social intercourse (Trower, Bryant, \& Argyle, 1978). It has mainly been developed as a social skills training programme for the treatment of mental disorders. Radley (1991) demonstrates that this approach overemphasizes the body as a means of control that conforms to the norms of society. Trower et al., (1978) for example, regard a person as socially inadequate 'if he is unable to affect the behaviour and feelings of others in the way that he intends and society accepts' (p. 2). According to Radley, this 'technolized' view of the body tends to overlook the body as a means of expression. Such a perspective on bodily skills is a very limited one, based as it is on the rather objectifying image of body techniques as something to be judged against an independent social standard and adjusted in accordance with those judgements. This approach to bodily skills is based on an instruction paradigm of communication rather then on a dialogical or co-regulative paradigm. However, as experiences in the field of sports, artistic expression and martial arts teach 
us, bodily skills are not learned by imposing a prescribed, so-called 'right' form upon individuals. They are learned by a process that involves the progressive development and refinement of bodily sensitivity. This sensitivity does not concern some private world of inner feelings, but on the contrary involves someone's bodily informed knowledge of the life-world. This means that bodily movements have to be felt from the inside as it were, so that they gradually become a part of one's own expressive register. It is not a matter of just imitating a prescribed form. Although the right forms or techniques have to be thoroughly trained, mastery is acquired only when those techniques become part of a personal style in which the expressive and the functional aspects of bodily movements fuse, as in dance, for example.

\section{Co-regulative Skills and the Regulation of Bodily Styles}

We have now moved quite far away from Harré's corporeal semantics. Harré borrows ideas from the structural semiotics of Roland Barthes (1985). It is striking, however, that Barthes's notions can be interpreted differently, more in accordance with the co-regulative skills paradigm we are proposing here. While Harré refers to Barthes in order to ground his theory of the body as a sign system, Douglas (1973) extensively quotes Barthes in order to elucidate her conception of style. Style, according to Barthes (1953/1968), springs from the body of the writer, from 'the depths of the author's personal and secret mythology' (p. 16). It is something which enfolds in a spontaneous way beyond his or her control, enacting in a non-representational way the 'erotic body' of the author (Barthes, 1973; Bernink, 1989). So Barthes acknowledges the body in its experiential and expressive qualities, but as was the case with Wiener et al., he also places this type of body outside the realm of the social, and equates it mistakenly with the idiosyncratic, 'secret mythology' of the writer. In addition Barthes places the social constitution and regulation of bodily style and the contribution of style to the production of meaning outside the reach of scientific examination. It is Douglas's merit to have put the notion of style back in the centre of her anthropological research of the body.

According to Douglas, the style of any message will coordinate all channels along which this message is given. Like Langer, she views the body not primarily as the producer of discrete signs. Instead, the signs and gestures of the body acquire their meaning by the expressive use of the body as a whole. Central in Douglas's anthropology of the body is her claim that a social system imposes pressure upon individuals to achieve consonance in all levels of experience, thereby producing concordance among the different means of expression. People are pressed to bring their physical experience into accordance with their social experience. Therefore the social order should be considered an embodied order, of which bodily practices and 
patterns of embodied experience and understanding are an integral part. So, while on the one hand society ritualizes its vital domains by both restricting and refining the possibilities for expression, on the other hand, people have to develop an expressive register or repertory which is sufficiently differentiated and geared to the social worlds in which they find themselves.

One way of applying Douglas's conception of bodily style to the field of social psychology is to connect it with our broadened theory of communication and interpersonal relationships. In fact, this involves a return to the features of non-verbal communication presented by Bateson some time ago (1972). He distinguished four features of this non-verbal mode of communication: it lacks unambiguous negations, tense and any identification of linguistic mood, and furthermore is metaphoric, which means that it communicates relations rather than statements about objects or things (p. 139). Like Langer, Bateson stressed the very specific ordering principles of this 'analogic' mode of communication. The lacking of negations, for example, brings about a specific range of problems. Two dogs which bump into one another cannot easily communicate they are not going to fight. Instead they have to perform a sham fight by the showing of fangs, engaging in a brawl and discovering that neither wants to kill the other (p. 141). This means that the regulation of non-verbal behaviour involves a clear-cut ritualization of expressive forms, consisting of multiple layers of 'signification'. Moreover, the example of the dogs demonstrates that a regulation of behaviour is possible without the need for a supra-individual moral order and without the explicit need for the discursive or linguistic negotiation of power differences. Instead, ordered forms of behaviour can emerge from the immediate co-regulation of expressive bodily activity.

\section{Anorexia Revisited}

Once the body is conceived of as a natural juncture of co-regulative skills, some conclusions with respect to the nature, diagnosis and research of anorexia nervosa can be drawn. Introducing the 'subjectified' or 'selfing' body into an explanation of anorexia places an emphasis on the competence of the subject to claim and sustain an identity. This competence is produced or constituted within a historical process but is nevertheless 'real' in the sense that it is objectified in durable bodily dispositions (Bourdieu, 1990). Viewed this way, anorexia nervosa is not a statement about, or a symbolic reference to, the social position of women, but the embodied expression of a culturally constituted subject. This has some implications for the diagnosis of anorexia.

The diagnostic criteria of anorexia nervosa which are currently used clearly demonstrate the significance of the body in this eating disorder. Both medical and psychological criteria play a part in this diagnosis, which relies 
on the four criteria of the DSM-IV (American Psychiatric Association, 1994).

First, there must be a persistent refusal to gain weight in spite of being about 15 percent below normal weight. A second criterion is amenorrhea, that is, a prolonged absence of the menstrual cycle. Third, the anorectic must experience an intense fear of gaining weight or becoming fat, and must claim to feel fat even when already underweight. The fourth criterion is the one which occasioned the most influential line of research into the psychological aspects of the body, the so-called 'distorted body image'. This research was inspired by an article of Bruch's (1962), in which she observed that anorexia nervosa involves a disorder of both the perception and experience of the body. Part of the discussion that followed her observations concerned the question of whether perceptual or cognitive factors are most important for an explanation of this distorted body image. Slade and Russell (1973), for example, maintained that the disorder is best understood as a disturbance of the way the body is perceived. However, most researchers emphasize the process of judgement-a cognitive process-in the realization of the body image (Garner \& Garfinkel, 1981; Huon \& Brown, 1986).

The way research on body-image distortion is carried out clearly demonstrates its departure from an objectified view of the body. The method applied in the greater part of this research consists of asking women to estimate as adequately as possible the width of their own body, using either simply drawn silhouettes or complex video distortion equipment. By comparing those estimates to their 'real' body size, it is determined whether the participant has a distorted representation of her own body. In our view, however, this type of research, even though it is related to the real or objective body size as part of a diagnostic criterion, obscures the true nature of the distorted relation anorectics have to their own body. When viewed from the co-regulative skill paradigm, body distortion looks different. According to this paradigm, a non-distorted relation to our bodies does not imply any reference to our objective body size. When walking through a small doorway, for example, we calculate neither the width of the doorway nor that of our bodies. Instead we are capable of acting quite adequately by using an unmediated, tacit knowledge of the environment and of our bodies (Gibson, 1966; Polanyi, 1967). This means that the perception of our bodies is to be understood not as a picture, constructed by ourselves as outside observers, but as an experience that is thoroughly intertwined with our experience of the 'life-world' (Merleau-Ponty, 1945/1962). This perspective raises some serious objections against an understanding of anorexia nervosa in terms of a distorted body image. It is not the image of the anorectic's body that seems to be distorted, but rather the relation to her social world; the selfing capabilities of her body are an integral part of this relationship. Therefore, we need to return to the expressive, communicative 
body as it was depicted in the preceding paragraphs, in order to examine whether this can provide any insights into the embodied nature of anorexia.

In the distorted image research, the body is not only objectified in the eye of the researcher. What this research does is to ask women to objectify their own body by judging it, as it were, from the outside. Yet, it is exactly this extreme objectification of their own body which constitutes the core of the anorectics' problem. The anorectic does not experience her body as something she is, but as something she has, as some sort of 'non-self'. It seems quite likely that the objectification of her own body keeps her from getting involved bodily in the social world in which she lives. Instead of being a vital constituent of a meaningful relation to her life-world, the body becomes an object of rigid control.

As we have tried to argue earlier, some feminists and social constructionists try to capture the bodily aspect of anorexia nervosa by reducing it to a cluster of discursively constructed meanings. However, as demonstrated above, those meanings pass over in silence the experiential and expressive body of the anorectic herself. By recognizing the central role of the body in the communicative, co-regulative interaction of the self and its social environment, we are able to view anorexia as a distortion of this selfing process. We avoid the static notion of self or self-concept, because what gets distorted is the process of becoming a self-the selfing process, as we call it. This is in accordance with our earlier emphasis on the bodily production of meaning rather than on the ascription of meaning to the body. Instead of asking for the meaning of the excessive slimming of anorectics, we should shift our attention to the competence of deploying their bodies in the social process.

Others as well have shifted the attention from deviant eating behaviour and dismissive judgements about the body to factors related to the self. They focus on social uncertainty and uncertainty about women's own feelings and emotions. By confronting this view with our own, we can make more precise what our view entails.

Anorectics are observed to be especially afraid of spontaneous, informal social relations (Appels, 1983; Bruch, 1977, 1978). Not only their eating behaviour, but their whole bodily style is characterized by restrained expressivity. Restrictive eating behaviour is only one-albeit the most conspicuous - aspect of the anorectic's bodily style. Anorectics are unable to join the vicissitudes of social interactions in an easy, relaxed way. Instead they seem to be constantly aware of themselves, hyper-sensitive to reactions of their social environment. Yet this type of sensitivity is misleading. In competently co-regulated activity there exists a largely automatic and unaware adjustment of one's behaviour to social situations. Anorectics don't seem able to enter into an easy flux of social interactions. They seem constantly preoccupied, watching and monitoring themselves in a rather 
laborious way. They keep a tight rein on their own doings. This precludes the rather self-evident and easy-going, subtle regulation of their own behaviour. Even though they are hyper-conscious of themselves, anorectics lack a social souplesse tailored to the demands of the social situation. In this regard, parents of anorectics often maintain that their daughters were obedient, conforming, non-assertive girls in their pre-anorectic period, which seems to be in sharp contrast with the stubborn and persistent behaviour they display later on in life (Bruch, 1978; Leon \& Finn, 1984).

This contrast has brought ego-psychological-oriented theorists, especially, to the conclusion that the anorectic develops a 'false self' or 'pseudo self', an enforced identity, based on the rigid control of her own body. This body control serves to conceal her feelings of worthlessness and lack of autonomy. Although the body thus becomes part of a some kind of identity project, we are faced again with the body as something which does not independently contribute to the production of meaning. The notion of a true and a false self easily overlooks the body's resilient contribution to the selfing process. Bateson (1972, pp. 309-337) already made clear that the idea of self-control is based on a mistaken and pathogenic epistemology in which the self is split up into a part that is controlled and a part by which the control is executed. We want to stress that the rigid body control of anorectics involves a practical dualism due to a lack of social souplesse. Anorectics experience the body as something they carry with them, something non-self. The mind, then, is imposed upon it as a device which holds firm control over all bodily processes, including expressivity. Bordo (1989) emphasizes the same extreme, dysfunctional dualism. According to her, anorectics are not just obsessed with body weight as such. They fear especially that the weak parts of their body (belly, breasts, buttocks, thighs) will escape their control. Bordo states that the fear of bulging body parts is in fact the 'anxiety about internal processes out of control-unrestrained desire, unrestrained hunger, uncontrolled impulse' (p. 89). By rigidly keeping a check on all of their bodily functions and processes, those women try to cover up their feelings of uncertainty and lack of social competence.

\section{Final Conclusions and Implications}

We can now draw some final conclusions about anorexia nervosa and what this disorder has to say about psychology's treatment of the body. Rendering the body of the anorectic as a mannequin that shows the effects of domination and submission, or as a battleground for feminist arguments, dilemmas and discourse, keeps hidden the anorectic's bodily production of meaning. Psychology's rather traditional occupation with discursive meaning holds sway over psychological thinking about the body. Yet anorexia nervosa is not just there to be interpreted as a message or a symptom which 
results in a judgement from the outside of what these women 'really' seem to convey. The view on communication as co-regulation, espoused in the preceding paragraphs, tries to shift the emphasis away from discursive meaning and messages to the production of meaning within the selfing process. This selfing process implies a social performance which is created out of the continual adjustment of the participants to one another. The minutiae of that process involve kinds of stylized bodily skills that testify to one's ability to take part in the life-world. The body thus becomes a natural juncture of co-regulative skills.

The anorectic's disturbance of bodily practice can now be described more adequately. This description will contain a message for psychology in the sense that psychology's focus should be more on what the body automatically brings about or fails to bring about. Psychology should be more concerned with the bodily production of meaning within the selfing process, instead of restricting itself to socially constructed judgements about the body. The failure of anorectics, if one may put it that way without morally judging those women, is a matter not so much of a distortion of their body image as of a lack of co-regulative skills that serve the selfing process. These skills are not developed adequately. In consequence, the women who suffer from anorexia are much more vulnerable to the pitfalls of an extreme dualistic relation to their own bodies, resulting in bodily dissatisfaction and need for mental control. Research which has been supportive of the view that this dualistic process is often involved frequently limits itself to the assessment of discourse about the body and fails to come to grips with the subtle details of co-regulation. Such theory and research fails to locate the disturbance in the domain of social skills and practices.

Although the emphasis on social skills and co-regulation suggests that the treatment of anorexia nervosa should focus on training and the corroboration of such skills from resources in the direct environment of the anorectic patient, the authors are not sufficiently clinically competent to draw the implications for therapeutic practice. They leave that to the experienced reader, who is invited to develop this view of the body in a full-scale psychological practice.

\section{References}

American Psychiatric Association. (1994). Diagnostic and statistical manual of mental disorders: DSM-IV. Washington, DC: Author.

Appels, A. (1983). Cultuur en ziekte [Culture and illness]. De Psycholoog, 18, 109-132.

Armon-Jones, C. (1986). The thesis of constructionism. In R. Harré (Ed.), The social construction of emotions. Oxford: Blackwell.

Averill, J.R. (1980). A constructivist view on emotion. In R. Plutchik \& H. Kellerman (Eds.), Emotion: Theory, research and experience: Vol 1. Theories of emotion. New York: Academic Press. 
Barthes, R. (1968). Writing degree zero (A. Lavers \& C. Smith, Trans.). New York: Hill \& Wang. (Original work published 1953.)

Barthes, R. (1973). Le plaisir du texte. Paris: Éditions du Seuil.

Barthes, R. (1985). The responsibility of form: Critical essays on music, art, and representations ( $\mathrm{R}$. Howard, Trans.). New York: Hill \& Wang.

Bateson, G. (1972). Steps to an ecology of mind. New York: Chandler.

Berger, P., \& Luckmann, T. (1966). The social construction of reality: A treatise on the sociology of knowledge Harmondsworth: Penguin.

Bernink, M. (1989). Inter(ventions) of the body: Preliminary study of the question of the body and sexual difference in Nietzsche, Barthes, Cixous and Irigaray. Doctoral thesis, University of Utrecht.

Billig, M. (1987). Arguing and thinking: A rhetorical approach to social psychology. Cambridge: Cambridge University Press.

Billig, M. (1988). Ideological dilemmas: A social psychology of everyday thinking. London: Sage.

Birdwhistell, R. (1952). Introduction to kinesics. Louisville, KY: University of Louisville Press.

Bordo, S.R. (1989). Reading the slender body. In M. Jacobus, E. Fox Keller, \& S. Shuttleworth (Eds.), Women, science and the body politic: Discourses and representations. New York: Methuen.

Boskind-Lodahl, M. (1976). Cinderella's stepsister: A feminist perspective on anorexia nervosa and bulimia. SIGNS: Journal of Women in Culture and Society, 2, 342-356.

Bourdieu, P. (1990). The logic of practice. Cambridge: Polity.

Bruch, H. (1962). Perceptual and conceptual disturbances in anorexia nervosa. Psychosomatic Medicine, 14, 187-195.

Bruch, H. (1973). Eating disorders: Obesity, anorexia nervosa and the person within. New York: Basic Books.

Bruch, H. (1978). The golden cage: The enigma of anorexia nervosa. Cambridge, MA: Harvard University Press.

Brumberg, J.J. (1988). Fasting girls: The emergence of anorexia nervosa as a modern disease. Cambridge, MA: Harvard University Press.

Butler, J. (1990). Gender trouble: Feminism and the subversion of identity. New York: Routledge.

Butler, J. (1993). Bodies that matter: On the discursive limits of 'sex'. New York: Routledge.

Chernin, K. (1986). The hungry self: Women, eating and identity. New York: Harper \& Row.

Douglas, M. (1973). Natural symbols: Explorations in cosmology. Harmondsworth: Penguin.

Dunbar, M. (1986). Catherine: The story of a girl who died of anorexia. Harmondsworth: Penguin.

Edwards, D. (1991). Categories for talking: On the cognitive and discursive bases of categorization. Theory \& Society, 1, 515-542.

Elias, N. (1978). The civilizing process. Oxford: Blackwell.

Fogel, A. (1993). Developing through relationships: Origins of communication, self and culture. New York: Harvester Wheatsheaf. 
Garfinkel, P.E., \& Garner, D.M. (1982). Anorexia nervosa: A multidimensional perspective. New York: Bruner.

Garner, D.M., \& Garfinkel, P.E. (1981). Body image in anorexia nervosa: Measurement, theory and clinical implications. International Journal of Psychiatry in Medicine, 38, 327-336.

Garner, D.M., Garfinkel, P.E., Schwartz, D., \& Thompson, M. (1980). Cultural expectations of thinness in women. Psychological Reports, 47, 483-491.

Gergen, K.J., \& Gergen, M.M. (1983). Narratives of the self. In T.R. Sarbin \& K.E. Scheibe (Eds.), Studies in social identity. New York: Praeger.

Gergen, K.J., \& Gergen, M.M. (1984). Social construction of narrative accounts. In K. Gergen \& M. Gergen (Eds.), Historical social psychology. Hillsdale, NJ: Erlbaum.

Gergen, K.J., \& Gergen, M.M. (1988). Narrative and the self as relationship. Advances in Experimental Social Psychology, 21, 17-56.

Gibson, J.J. (1966). The senses considered as perceptual systems. Boston, MA: Houghton Mifflin.

Harré, R. (1986). The social contructionist viewpoint. In R. Harré (Ed.), The social construction of emotions. Oxford: Blackwell.

Harré, R. (1991). Physical being: A theory for a corporeal psychology. Oxford: Blackwell.

Harré, R., \& Gillet, G. (1994). The discursive mind. London: Sage.

Heelas, P. (1981). Emotion talk across cultures. In P. Heelas \& A. Lock (Eds.), Indigenous psychologies: The anthropology of the self. London: Academic Press.

Hermans, H.J.M., \& Kempen, H.J.G. (1993). The dialogical self: Meaning as movement. San Diego CA: Academic Press.

Hermans, H.J.M., Kempen, H.J.G., \& Loon, R.J.P. van (1992). The dialogical self: beyond individualism and rationalism. American Psychologist, 47, 23-33

Hochschild, A.R. (1983). The managed heart: Commercialization of human feeling. Berkeley: University of California Press.

Huon, G.F., \& Brown, L.B. (1986). Body images in anorexia nervosa and bulimia nervosa. International Journal of Eating Disorders, 5, 421-439.

Jaggar, A.M. (1983). Feminist politics and human nature. Totowa, NJ: Rowman \& Allenhed.

Jaggar, A.M., \& Bordo, S.R. (1992). Gender/body/knowledge: Feminist reconstructions of being and knowing. New Brunswick, NJ: Rutgers University Press.

Kitzinger, C. (1987). The social construction of lesbianism. London: Sage.

Kitzinger, C. (1992). Theorizing heterosexuality. Feminism \& Psychology, 2, 293-324.

Kristeva, J. (1978). Gesture: Practice or communication? (J. Benthall, Trans.). In T. Polhemus (Ed.), The body reader: Social aspects of the human body. New York: Pantheon. (Reprinted from Languages, 1968, 10, 48-64.)

Langer, S.K. (1951). Philosophy in a new key: A study in the symbolism of reason, rite and art. London: Oxford University Press.

Lawrence, M. (1984). The anorectic experience. London: Women's Press.

Leon, G.R., \& Finn, S. (1984). Sex-role stereotypes and the development of eating disorders. In C. Spatz Widom (Ed.), Sex roles and psychopathology. New York: Plenum. 
Lenning, A. van (1990). Anorexie: Ben kritisch commentaar op de cultuur? [Anorexia: A critical comment on culture?]. Tijdschrift voor Vrouwenstudies, 42, 128-142.

Lutz, C. (1986). The domain of emotion words in Ifaluk. In R. Harré (Ed.), The social construction of emotions. Oxford: Blackwell.

Lutz, C. (1988). Unnatural emotions. Chicago: University of Chicago Press.

Macleod, S. (1982). The art of starvation: One girl's journey through adolescence and anorexia: A story of survival. London: Virago.

Mauss, M. (1973). The techniques of the body (B. Brewster, Trans.). Economy and Society, 2, 70-88. (Reprinted from Journal de Psychologie Normale et Pathologique, 1935, 32.)

Merleau-Ponty, M. (1962). Phenomenology of perception (C. Smith, Trans.). London: Routledge \& Kegan Paul. (Original work published 1945.)

Merwe, W.L. van der, \& Voestermans, P.P. (1995). Wittgenstein's legacy and the challenge to psychology. Theory \& Psychology, 5, 27-48.

Minuchin, S., Rosman, B.L., \& Baker, L. (1978). Psychosomatic families: Anorexia nervosa in context. Cambridge, MA: Harvard University Press.

Orbach, S. (1985). Hunger strike: The anorectic's struggle as a metaphor for our age. New York: Plenum.

Polanyi, M. (1967). The tacit dimension. London: Routledge.

Potter, J., \& Wetherell, M. (1987). Discourse and social psychology. Newbury Park, CA: Sage.

Radley, A. (1991). The body in social psychology. New York: Springer.

Ratner. C. (1989). A social constructionist critique of the naturalistic theory of emotion. The Journal of Mind and Behavior, 10, 211-230.

Sampson, E.E. (1993). Identity politics: Challenges to psychology's understanding. American Psychologist, 48, 1219-1230.

Sarbin, T.R. (Ed.). (1986a). Narrative psychology: The storied nature of human conduct. New York: Praeger.

Sarbin, T.R. (1986b). Emotion and act: Roles and rhetoric. In R. Harré (Ed.), The social construction of emotions. Oxford: Blackwell.

Scheflen, A.E. (1972). Body language and social order: Communication as behavioral control. Englewood Cliffs, NJ: Prentice Hall.

Selvini-Palazzoli, M. (1974). Self starvation: From the intrapsychic to the transpersonal approach to anorexia nervosa. London: Chaucer.

Shotter, J. (1993). Conversational realities: Constructing life through language. London: Sage.

Shotter, J. (1995). In conversation: Joint action, shared intentionality and ethics. Theory \& Psychology, 5, 49-73.

Shotter, J., \& Gergen, K. (1989). Texts of identity. London: Sage.

Slade, P.D., \& Russell, G.F.M. (1973). Awareness of body dimensions in anorexia nervosa: Cross-sectional and longitudinal studies. Psychological Medicine, 3, 188-199.

Terwee, S. (1995). Deconstructing social constructionism. In I. Lubek, R. van Hezewijk, G. Pheterson, \& C. Tolman (Eds.), Trends and issues in theoretical psychology. New York: Springer.

Thomä, H. (1967). Anorexia nervosa. New York: International University Press. 
Trower, P., Bryant, B., \& Argyle, M. (1978). Social skills and mental health. London: Methuen.

Unger, R.K. (1989). Representations: Social constructions of gender. Amityville, NY: Baywood.

Unger, R.K. (1992). Women and gender: A feminist psychology. Philadelphia, PA: Temple University Press.

Varela, F.J., \& Maturana, H.R. (1984). The tree of knowledge: The biological roots of human understanding. Boston, MA: Shambala.

Varela, F.J., Thompson, F., \& Rosch, E. (1991). The embodied mind: Cognitive science and human experience. Cambridge, MA: MIT Press.

Vroman, L. (1957). Mens [Human being]. In Uit slaapwandelen. Amsterdam: Querido.

Waller, J.V., Kaufman, M.R., \& Deutsch, F. (1940). Anorexia nervosa: A psychosomatic entity. Psychosomatic Medicine, 2, 2-13.

Wiener, M., Devoe, S., Rubinow, S., \& Geller, J. (1972). Nonverbal behavior and nonverbal communication. Psychological Review, 79, 185-214.

Wiseman, C.V., Gray, J.J., Mosimann, J.E., \& Aherens, A.H. (1992). Cultural expectations of thinness in women: An update. International Journal of Eating Disorders, 11, 85-89.

Cor BAERveldt is a Junior Researcher in the Department of Cultural Psychology, University of Nijmegen. He obtained his master's degree with a thesis on the cultural constitution of expressive bodily skills, especially in relation to eating disorders. He is currently working on a dissertation on New Age practices. His main fields of interest are the epistemological foundations of the human sciences, human embodiment and the cultural constitution of self. ADDREss: Nijmegen Cultural Psychology Group (NCPG), University of Nijmegen, PO Box 9104, 6500 HE Nijmegen, The Netherlands. [email: baerveldt@psych.kun.nl]

Paul Voestermans is Associate Professor of Cultural Psychology at the University of Nijmegen. His research has focused on theories of culture and their application to the cultural patterning of behaviour. His main area of interest is the cultural and embodied forms of feeling. He has published several articles in Dutch and English dealing with this theme of emotion and feeling, embodiment and culture. ADDREss: Nijmegen Cultural Psychology Group (NCPG), University of Nijmegen, PO Box 9104, $6500 \mathrm{HE}$ Nijmegen, The Netherlands. [email: voestermans@psych.kun.nl] 